\title{
INCLUSÕES FLUIDAS EM GRANULITOS E CAMINHOS P-T-t RETROMETAMÓRFICOS PARA O COMPLEXO JUIZ DE FORA
}

\author{
JOSÉ RENATO NOGUEIRA ${ }^{1}$, ASIT CHOUDHURI ${ }^{2}$ \& ROSA MARIA DA SILVEIRA BELLO ${ }^{3}$
}

\begin{abstract}
FLUID INCLUSIONS IN GRANULITES AND RETROMETAMORPHIC P-T-t PATHS FOR THE JUIZ DE FORA COMPLEX, SOUTHEASTERN BRAZIL Fluid inclusion analyses in granulitic rocks are presented as an important source for relevant petrogenetic data for the study of the metamorphic evolution of the Juiz de Fora Tectonic Domain (DTJF) - Ribeira Belt, in the southwest Juiz de Fora (MG) region. The area is characterized by an intense "mixing" between basement units, composed by hornblende gneisses and orthogranulites of the Juiz de Fora Complex, and metasedimentary units, correlated to the Andrelândia

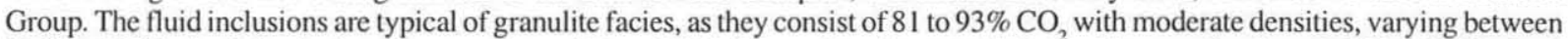
0.79 and $0.94 \mathrm{~g} / \mathrm{cm}^{3}$, for the basement rocks; and 92 to $100 \% \mathrm{CO}_{2}$, and moderate to high densities varying from 0.916 to $1.068 \mathrm{~g} / \mathrm{cm}^{3}$ for the metasediments of DTJF. The fluids associated to basement rocks have shown that the latest formed inclusions (trails) present systematically higher densities than the earlier ones (isolated), pointing to a near isobaric cooling retrometamorphic path, during the Transamazonian Event. The likely P-T-t path for the Andrelândia Group supracrustal rocks, defined by a pattern of progressive lowering in inclusion densities (from $\mathrm{D}_{2}$-phase to $\mathrm{D}_{4}$-phase associated samples), indicates a more significant decrease in pressure than temperature after the metamorphic peak, suggesting an isothermal decompression situation, with a clockwise P-T-t path for the Brasiliano Event. The available data for structural domains where basement rocks prevail indicate that the granulite facies metamorphism can be related to a Transamazonian extensional tectonic event, associated to magmatic intra and underplating, providing $\mathrm{CO}_{2}$-rich fluids derived from mafic rocks and the necessary excess heat to the older granulite metamorphism $\left(4-6 \mathrm{~kb} / 800-850^{\circ} \mathrm{C}\right)$. During the Brasiliano, the collisional event that generated the Ribeira Belt caused intense anatexis that possibly removed large amounts of $\mathrm{H}_{2} \mathrm{O}$ from the system, leading the metasediments to reach granulite facies metamorphism during the Brasiliano Event, with temperatures not higher than $800^{\circ} \mathrm{C}$ and pressures between 6-7 kb.
\end{abstract}

Keywords: granulite, fluids, P-T paths, Juiz de Fora Complex

Resumo A análise de inclusões fluidas em rochas granulíticas é apresentada como uma importante fonte geradora de dados petrogenéticos relevantes no estudo da evolução metamórfica de uma porção do Domínio Tectônico Juiz de Fora (DTJF) na Faixa Ribeira, na região a sudoeste de Juiz de Fora (MG). A área estudada é caracterizada por uma intensa intercalação entre unidades de embasamento, constituidas por hornblenda ortognaisses e ortogranulitos do Complexo Juiz de Fora, e unidades metassedimentares essencialmente compostas de granada-biotita gnaisses, correlacionáveis ao Grupo Andrelândia. As inclusões estudadas são típicas de fácies granulito, possuindo de 81 a $93 \%$ de $\mathrm{CO}_{2}$, com densidades moderadas, variando entre $0,79 \mathrm{e} 0,94 \mathrm{~g} / \mathrm{cm}^{3}$, para as rochas do embasamento; e 92 a $100 \%$ de $\mathrm{CO}_{2}$, e densidades moderadas a altas, oscilando entre $0,916 \mathrm{e} 1,068 \mathrm{~g} / \mathrm{cm}^{3}$ para a porção metassedimentar do DTJF. Os fluidos associados à̀s rochas do embasamento revelam que as últimas inclusões formadas (em trilhas) apresentam sistematicamente densidades maiores do que as primeiras inclusões a serem aprisionadas (isoladas), sinalizando para um caminho retrometamórfico com resfriamento aproximadamente isobárico, durante o Evento Transamazônico. O provável caminho P-T-t sofrido pelas rochas supracrustais do Grupo Andrelândia, definido com base no padrão de diminuição progressiva das densidades das inclusões (indo desde as amostras associadas à fase $\mathrm{D}_{2}$ até $\mathrm{a}$ fase $\mathrm{D}_{4}$ ), aponta para uma diminuição de pressão mais significativa do que a diminuição de temperatura após o pico metamórfico, configurando uma situação de descompressão aproximadamente isotérmica, com um caminho P-T-t horário para o Evento Brasiliano. Os dados existentes para os domínios estruturais onde predominam rochas do embasamento, indicam que o metamorfismo de fácies granulito pode estar relacionado a um evento tectônico extensional Transamazônico, com a formação de intra e underplating magmático, provendo fluidos ricos $\mathrm{em} \mathrm{CO}_{2}$ oriundos das rochas máficas e excesso de calor necessário ao metamorfismo granulítico mais antigo $\left(4-6 \mathrm{~kb} / 800-850^{\circ} \mathrm{C}\right)$. Durante o Evento Brasiliano, o evento colisional que gerou a Faixa Ribeira causou intensos processos anatéticos que possivelmente retiraram grandes quantidades de $\mathrm{H}_{2} \mathrm{O}$ do sistema, fazendo com que os metassedimentos atingissem a fácies granulito, resultando no metamorfismo granulítico Brasiliano, com temperaturas máximas de $800^{\circ} \mathrm{C}$ e pressões entre 6 e $7 \mathrm{~kb}$.

Palavras-chave: granulito, fluidos, caminhos P-T, Complexo Juiz de Fora

INTRODUÇÃO O estudo de inclusões fluidas em rochas de fácies granulito vem se desenvolvendo desde o início da década de 1970, quando foi descoberto que muitos granulitos contém inclusões fluidas ricas em $\mathrm{CO}_{2}$ (Touret 1971). Estas têm sido interpretadas como aprisionadas durante o pico do metamorfismo naquela fácies. Entretanto, certos exemplos mostram que algumas inclusões ricas em $\mathrm{CO}_{2}$ devem ter sido aprisionadas após o pico metamórfico (Lamb et al. 1987). As condições reinantes durante o caminho progressivo não podem ser detectadas, uma vez que as características físicas e químicas das inclusões são obliteradas, na medida em que se adaptam ao aumento de pressão e temperatura.

Este trabalho aborda os caminhos retrometamórficos das rochas granulíticas do Complexo Juiz de Fora, pela análise do comportamento de isócoras obtidas a partir de inclusões fluidas ricas

1 - Departamento de Geologia Regional e Geotectônica, Faculdade de Geologia, Universidade do Estado do Rio de Janeiro. TEKTOS - Grupo de Pesquisa em Geotectônica. Rua São Francisco Xavier 524, sala A-4034, Maracanã, Rio de Janeiro, Brasil. CEP 20559-900. E.mail: jrnog@uerj.br

2 - Departamento de Metalogênese e Geoquímica, Instituto de Geociências, Universidade Estadual de Campinas, Cidade Universitária Zeferino Vaz, Barāo Geraldo. Caixa Postal 6152, CEP 13081-970, Brasil.

3 - Instituto de Geociências - Universidade de São Paulo. Rua do Lago 562 - CEP - 05508-080 - São Paulo, SP. 
em $\mathrm{CO}_{2}$, diferenciadas cronologicamente pelas suas distintas classes (primárias, pseudo-secundárias e secundárias). Inclusões fluidas aprisionadas em ortogranulitos durante o pico metamórfico do Evento Transamazônico são analisadas a partir de valores de temperaturas de fusão e homogenização, e comparadas com fluidos aprisionados em metassedimentos deste complexo, durante as diferentes fases de deformação do Evento Brasiliano.

CONTEXTO GEOLÓGICO A área estudada está localizada a SW de Juiz de Fora (MG), próximo a Monte Verde e é caracterizada por uma intercalação de ortognaisses constituidos por hornblenda gnaisses e granulitos, e unidades metassedimentares compostas por granada-biotita gnaisses e muscovita quartzitos. Também ocorrem corpos de leucograníto e charnockítico associados à fusão parcial dos metassedimentos (Fig. 1).

Os estudos de metamorfismo apontam para existência de dois eventos tectono-termais com condições de pressão e temperatura distintas, que afetaram ambos conjuntos litológicos principais e geraram associações minerais de fácies granulito. O último evento é seguramente relacionado ao Ciclo Brasiliano, com idades entre 610-490 Ma (Machado et al. 1996) e afetou tanto os ortognaisses do embasamento como as rochas supracrustais correlacionáveis em grande parte na área ao Grupo Andrelândia, depositado entre 1.0 e $0.6 \mathrm{Ga}$ (Ribeiro et al. 1995). O metamorfismo relacionado ao evento anterior ao Brasiliano atingiu apenas os ortognaisses do embasamento e é correlacionável ao Transamazônico, com idades entre 2.2-1.9 Ga (Machado et al. 1996).

As estruturas geradas no Ciclo Brasiliano foram analisadas por domínios estruturais e evidenciam sua associação com uma tectônica compressiva progressiva, inicialmente com características tangenciais, de vergência de SE para NW, culminando com a formação de estruturas em "amêndoas" durante a fase direcional de maior intensidade (Nogueira 1999).

A relação entre as estruturas pode ser entendida segundo uma evolução contínua, onde um ambiente de tectônica tangencial foi gradualmente substituída por outro dominantemente direcional, ambos relacionados à fase $\mathrm{D}_{2}$, culminando com movimentação transcorrente durante a fase $\mathrm{D}_{3}$. Nos estágios finais do Brasiliano houve inversão tectônica e geração de milonitos tardios $\left(D_{4}\right)$, pegmatitos e leucogranitos, que podem estar associados a um estágio de "relaxamento" crustal ou de abatimento do orógeno (Nogueira \& Choudhuri 2000).

\section{CLASSIFICAÇÃO E CONDIÇÕES DE APRISIONAMENTO} DAS INCLUSỎ ES FLUIDAS O esquema mais útil de classificação das inclusões fluidas se baseia na sua origem: primária, pseudosecundária e secundária (Roeder 1981). Outro baseia-se na natureza do fluido na época do aprisionamento, ou seja, se homogêneo ou heterogêneo. Estima-se que em mais de $99 \%$ dos casos as inclusões são aprisionadas a partir de fluidos homogêneos (Roeder 1981), embora Shepherd et al. (1985; p.70) mostrem que o sistema $\mathrm{H}_{2} \mathrm{O}+\mathrm{NaCl}+\mathrm{CO}_{2}$ permite o aprisionamento de inclusões a partir de um sistema heterogêneo, mesmo em condições de alta temperatura. Entretanto, como adiante descrito, este não é o caso das inclusões estudadas neste trabalho.

As inclusões primárias se formam durante o crescimento do cristal hospedeiro, e se caracterizam por ocorrerem isoladas ou em aglomerados isolados de inclusões não alinhadas. Fraturamentos ocorridos na presença de fluidos, durante o crescimento do cristal, podem gerar inclusões pseudosecundárias, que geralmente se distribuem em trilhas internas ao cristal. Se as fraturas são formadas em qualquer tempo após o crescimento do cristal, podem gerar

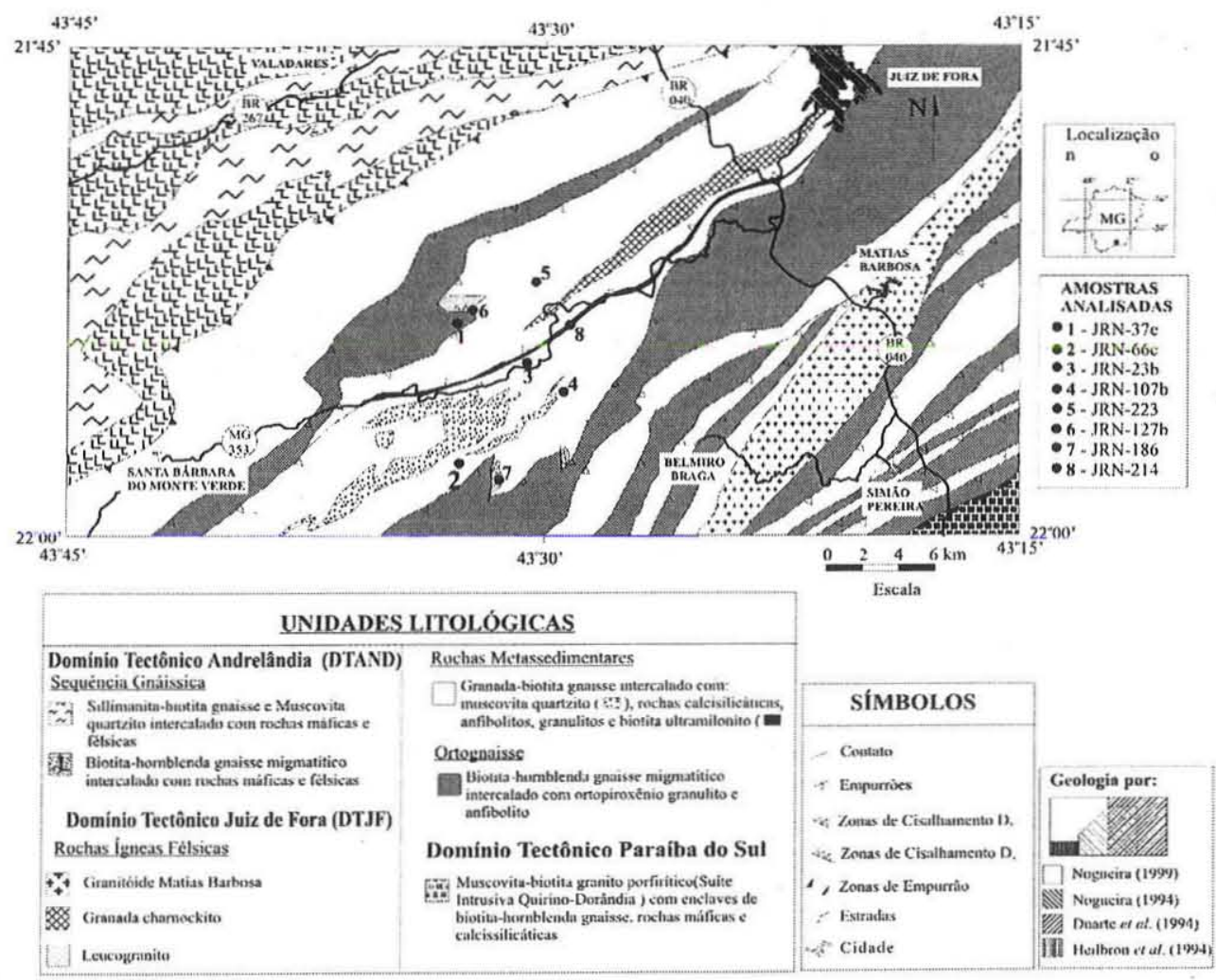

Figura 1 - Mapa geológico detalhado da área a sudoeste de Juiz de Fora, com localização das amostras analisadas. 
inclusões secundárias, dispostas em trilhas que cortam mais de um cristal.

Esta classificação permite determinar uma ordem cronológica de formação das inclusões que, das mais antigas às mais novas, compreendem as isoladas, em aglomerados, em trilhas intracristalinas e em trilhas intercristalinas. Contudo, as inclusões isoladas e em aglomerados podem pertencer à mesma geração.

Durante o retrometamorfismo, inclusões anteriormente aprisionadas podem ter suas características físicas e químicas originais modificadas. Dentre as várias modificações, destacam-se:

- necking down- divisão de uma inclusão originalmente maior em várias menores;

- aporte e escape de fluidos na inclusão (leakage in or out) quando ocorrem gradientes de pressão entre a inclusão e o meio externo, pode ocorrer, durante a deformação, a abertura de uma inclusão e preenchimento por aporte de novos fluidos, ou escape de fluidos;

- crepitação - ocorre quando a pressão interna do fluido for suficientemente maior do que a pressão confinante, devido ao soerguimento, causando fraturamento do mineral encaixante como forma de alívio de pressão, resultando em inclusões vazias.

Estes fenômenos alteram as características iniciais de aprisionamento de uma inclusão e causam variação nas temperaturas de mudanças de fase medidas em laboratório.

MÉTODOS ANALÍTICOS Os dados analíticos foram obtidos a partir de seções bipolidas, analisadas em parte no Laboratório de Microtermometria do Instituto de Geociências/Unicamp, com equipamento Linkan TMSG-600 de resfriamento-aquecimento, acoplado a um microscópio JENAPOL-ZEISS, e ainda no Instituto de Geociências/USP, com equipamento microtermométrico ChaixMeca, MTM85, também ligado a um microscópio petrográfico. Ambos permitem resfriamento até $-180^{\circ} \mathrm{C}$ por circulação de nitrogênio em condutor interno. As temperaturas foram medidas por registradores automáticos digitais.

Em laboratório, é possível determinar, em inclusões ricas em $\mathrm{CO}_{2}$, as temperaturas de fusão, que indicam o grau de pureza neste componente $\left(-56,6^{\circ} \mathrm{C}\right.$ para inclusões com $\mathrm{CO}_{2}$ puro) e de homogeneização, variáveis de acordo com a densidade da inclusão.

Medidas as temperaturas de fusão e homogeneização de $\mathrm{CO}_{2}$ $\left(\mathrm{Tf}_{\mathrm{CO} 2}\right.$ e $\left.\mathrm{Th}_{\mathrm{CO} 2}\right)$ foram efetuadas em cerca de 1400 inclusões fluidas. A incerteza sobre os valores de temperatura é de $+/-0,1^{\circ} \mathrm{C}$. O tratamento estatístico dos dados foi feito a partir de histogramas de frequência separados por amostras e tipos de inclusão (isoladas, aglomerados, trilhas e trilhas intergrãos).

A partir destes dados e das equações gerais de estado de um gás, obtém-se as isócoras, que são curvas de mesma densidade num campo P-T. As isócoras, quando dispostas no diagrama P-T, podem ou não intersectar o campo de pico metamórfico, previamente estabelecido pela posição de curvas de isorreação ou por geotermobarometria.

Foi escolhido o sistema binário $\mathrm{CO}_{2}-\mathrm{CH}_{4}$ para a determinação das isócoras. Estimativas feitas com o sistema $\mathrm{CO}_{2}-\mathrm{N}_{2}$ mostraram um aumento aproximado de $0,4 \mathrm{~kb}$ nas pressões obtidas, em relação ao sistema $\mathrm{CO}_{2}-\mathrm{CH}_{4}$, nas inclusões que apresentaram um maior grau de contaminação (19\%). Pela análise dos diagramas de fases dos sistemas $\mathrm{CO}_{2}-\mathrm{CH}_{4}, \mathrm{CO}_{2}-\mathrm{N}_{2}$ e CO$-\mathrm{CH}_{4}-\mathrm{N}_{2}$ (Kerkhof 1990), o baixo grau de contaminação das inclusões estudadas possibilita a utilização de um destes dois sistemas binários na obtenção das isócoras, sem haver necessidade do uso de espectroscopia, gerando resultados com uma margem de erro aceitável.
A determinação da isócoras foi feita com o p^ograma FLINCOR (Brown 1989), usando-se dados de temperaturas de transição de fases, volume molar e fração molar de $\mathrm{CH}_{4}$, obtidos a partir dos gráficos desenvolvidos por Swanemberg (1979), Kerkhof (1990), Brown \& Lamb (1989) e Heyen et al. (1982).

MICROTERMOMETRIA Os estudos de inclusões fluidas foram realizados em ortogranulitos do Complexo Juiz de Fora e em granulitos considerados como enclaves tectônicos destas porções em metassedimentos. Também foram estudadas inclusões nos metassedimentos, aprisionadas em condições de facies granulito. O estudo visou a análise das inclusões aprisionadas em etapas próximas aos picos metamórficos granulíticos das rochas do embasamento e das supracrustais. As amostras foram selecionadas com o intuito de comparar as condições de pressão parcial de fluidos de granulitos do embasamento com as dos metassedimentos e subsidiar uma análise dos diferentes caminhos retrometamórficos durante cada evento tectônico.

Fluidos dos Ortogranulitos Nos ortognaisses, optou-se por estudar as inclusões fluidas em três amostras com ortopiroxênio. Utilizou-se uma amostra típica do embasamento (JRN-37e) e duas de enclaves tectônicos nos metassedimentos, com aspectos semelhantes aos seus correspondentes do embasamento. Das duas amostras intercaladas em metassedimentos, uma é de zona milonítica próxima ao contato com o embasamento, a sul da área (JRN-66c), e a outra é da região central da faixa principal de metassedimentos, mas localizada próximo à faixa milonítica (JRN23b). Na última estudou-se separadamente bandas félsicas (JRN23b I) e máficas (JRN-23b II).

GRANULITO FÉLSICO - AMOSTRA JRN-37e Petrograficamente, esta amostra tem textura granoblástica e seus minerais, em ordem decrescente de abundância, são plagioclásio, hornblenda, Kfeldspato, quartzo, ortopiroxênio, minerais opacos e biotita. As temperaturas foram determinadas em cristais de plagioclásio e Kfeldspato, e os resultados analisados separadamente.

Os histogramas de temperaturas de fusão e homogeneização de $\mathrm{CO}_{2}$ (Fig. 2) mostram que os picos ocorrem respectivamente a $58.8 \mathrm{e}-11.0^{\circ} \mathrm{C}$. O histograma de temperaturas de homogeneização de todas inclusões (Fig. 2b), monstra grande dispersão dos valores de inclusões com necking down e, por isto, não foram computadas na obtenção das isócoras.

Os histogramas individuais de plagioclásio e K-feldspato mostram que a variação dos valores é causada pelas inclusões fluidas em K-feldspato. Isto decorre do fato de que a temperatura de recristalização do K-feldspato ser menor do que a do plagioclásio, permitindo que este último preserve inclusões aprisionadas em condições mais próximas do pico metamórfico.

Entretanto, para obter as isócoras, foram usados para todas as amostras os valores máximos e mínimos observados na região de pico dos histogramas. Isto permite obter isócoras que delimitem um campo que engloba a formação de cada tipo de inclusão. Neste esquema, as temperaturas de homogeneização são mais importantes enquanto que para as temperaturas de fusão valores de pico dos histogramas podem ser mais adequados.

As figuras 3 e $4^{*}$ apresentam as isócoras e o campo de pico metamórfico. A curva mínima dos aglomerados em K-feldspato não intersecta este campo, sugerindo mudanças posteriores nas características das inclusões, durante processos pós-metamórficos. Exceto por esta curva, um padrão para as curvas máximas e míni- 
mas pode ser detectado nestas duas figuras. Neste padrão, as curvas de inclusões em trilhas têm densidades maiores do que inclusões em aglomerados, que por sua vez tem densidades maiores do que as inclusões isoladas. A Tabela 1 mostra os valores usados na determinação das isócoras.

GRANULITO MÁFICO - AMOSTRA JRN-66c Esta amostra corresponde a um granulito máfico composto de plagioclásio, quartzo, hornblenda, ortopiroxênio e subordinadamente biotita e $\mathrm{K}$-feldspato. Apesar de intercalada nos metassedimentos, esta amostra é mesoscopicamente semelhante ao das rochas do embasamento. Por ter sido coletada perto de uma zona de empurrão, pode ser interpretada como enclave tectônico do embasamento nos metassedimentos, e os resultados apresentados a seguir corroboram esta interpretação na medida em que se mantém o padrão encontrado nas rochas do embasamento.

As temperaturas de fusão e homogeneização ( $\mathrm{Tf}$ e $\mathrm{Th}$ ) foram medidas em cristais de plagioclásio, mais raramente em quartzo. $\mathrm{O}$ histograma de frequência das temperaturas de fusão consta da figura 5 a. $\mathrm{O}$ pico para todas as inclusões situa-se a $-58,4{ }^{\circ} \mathrm{C}$, enquanto que o das inclusões em trilhas a $-58,8^{\circ} \mathrm{C}$, de aglomerados a $-58,5^{\circ} \mathrm{C}$ e isoladas a $-58,4^{\circ} \mathrm{C}$. Estas temperaturas indicam que inclusões isoladas apresentam maior grau de pureza em $\mathrm{CO}_{2}$.

No histograma das temperaturas de homogeneização (fig. 5b) observa-se que o pico geral situa-se em $-10,6^{\circ} \mathrm{C}$, enquanto nas inclusões em trilhas e isoladas em $-11,4^{\circ} \mathrm{C}$ e em aglomerados em $-9,8^{\circ} \mathrm{C}$.

A Tabela 2 lista os valores usados na determinação das isócoras. A figura 6 mostra o mesmo padrão detectado na amostra anterior. A isócora mínima para inclusões isoladas aponta para alterações pós-metamórficas das características deste tipo de inclusão.

GRANULITO BANDADO - AMOSTRA JRN-23b Esta amostra, coletada próxima de uma zona de empurrão (Fig. 1), é também considerada como uma enclave tectônica do embasamento e apresenta bandamento máfico-félsico similar ao encontrado nas rochas do embasamento. Estas bandas foram analisadas separadamente. Além disto, a porção máfica (JRN-23b II) apresenta intercrescimento entre granada e clinopiroxênio ou bordos de granada secundária em clinopiroxênio. Esta banda tem textura granoblástica e é composta por plagioclásio, ortopiroxênio, granada, clinopiroxênio e hornblenda.

Em lâmina delgada, a porção félsica (JRN-23b I) contém feldspatos fraturados e algumas texturas de forte deformação. Esta consiste de plagioclásio, clinopiroxênio com bordos de hornblenda, quartzo, $\mathrm{K}$-feldspato, minerais opacos, titanita, escapolita e apatita.

BANDA FÉLSICA - JRN-23B I As análises de inclusões fluidas foram feitas principalmente em quartzo, subordinadamente em feldspatos. Os histogramas de Tf e Th (Fog. 7) incluem trilhas intergrãos. Nota-se a presença de um grupo de trilhas com Tf em torno de $-60,7^{\circ} \mathrm{C}$ e Th em torno de $-31^{\circ} \mathrm{C}$, o que provavelmente reflete uma maior contaminação do fluido rico em $\mathrm{CO}_{2}$.

As isócoras constam da figura 8 e os dados figuram na Tabela 3. Na figura 8 nota-se que inclusões em trilhas e aglomerados mostram padrões similares em comparação com as amostras previamente descritas. Por outro lado, inclusões isoladas possuem densidades um pouco mais elevadas do esperado pelo padrão até aquí descrito. A inversão no comportamento das isócoras no diagrama P-T pode ser explicada pela contaminação por fluidos oriundos dos metassedimentos, e que foram aprisionados por novos grãos recristalizados de quartzo. Isto é sustentado pela análise
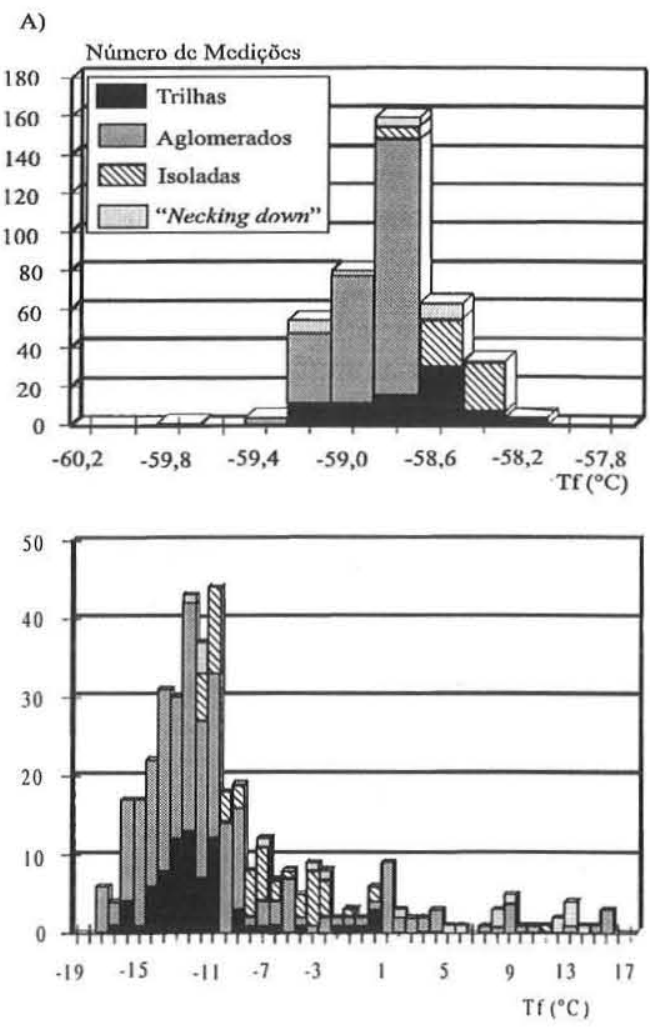

Figura 2 - Histogramas de temperaturas de fusão e homogeneização de $\mathrm{CO}_{2}$ (Tf and Th respectivamente) para todos os tipos de inclusões em cristais de K-feldspato e plagioclásio (amostra JRN-37e).

$\mathrm{P}(\mathrm{kb})$

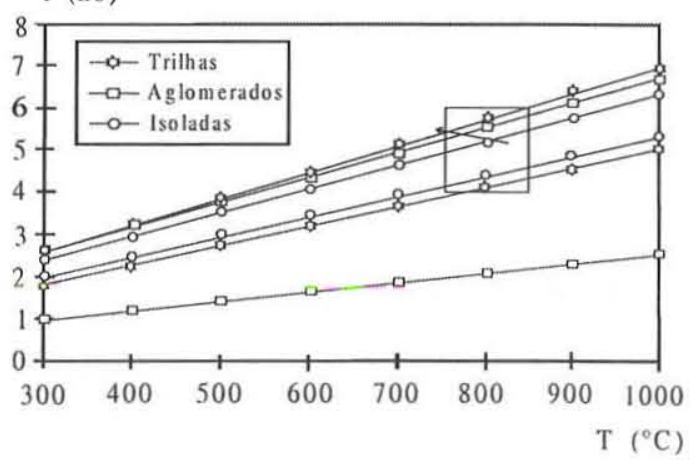

Figura 3 - Isócoras obtidas para inclusões fluidas em cristais de $K$-feldspato (amostra JRN-37e).

dos fluidos dos metassedimentos, abordados a seguir..

BANDA MÁFICA - JRN-23B II Nestā amostra, foram analisadas inclusões em plagioclásio, subordinadamente K-feldspato. Foi possível observar algumas inclusões isoladas em bordos de piroxênio que não apresentaram valores anômalos, em relação às inclusões em K-feldspato e plagioclásio. Nas seções bipolidas, a medição de temperaturas de mudanças de fase em cristais que absorvem menos luz (granada, piroxênios e hornblenda) é geralmente difícil de ser feita e onde é possível observar maior transpa- 
Tabela 1 - Valores usados para a determinação das isócoras para inclusões fluidas em $K$-feldspato e plagioclásio. Tf and Th são respectivamente temperaturas de fusão $e$ homogeneização de $\mathrm{CO}_{2}$ e d é densidade $\left(\mathrm{g} / \mathrm{cm}^{3}\right)$.

\begin{tabular}{ccccccc}
\multicolumn{1}{c}{ Trilhas } & \multicolumn{2}{c}{ Aglomerados } & Isoladas \\
\hline JRN-37e & máx. & Mín. & $\begin{array}{c}\text { máx. } \\
\text { K-feldspato }\end{array}$ & mín. & máx. & min. \\
\hline Tf & -58.2 & -58.8 & -58.8 & -58.9 & -58.4 & -58.4 \\
Th & -15.5 & 0,5 & -17.0 & 16 & -10.5 & -3.0 \\
D & 0,94 & 0,82 & 0,91 & 0,58 & 0,9 & 0,85 \\
\hline \multicolumn{7}{c}{ Plagioclásio } \\
\hline Tf & -58.8 & -58.8 & -58.8 & -58.9 & -58.6 & -58.6 \\
Th & -14.0 & -10.0 & -15.0 & -9.0 & -10.5 & -7.0 \\
D & 0,92 & 0,89 & 0,9 & 0,86 & 0,89 & 0,85 \\
\hline
\end{tabular}

$\mathrm{P}(\mathrm{kb})$

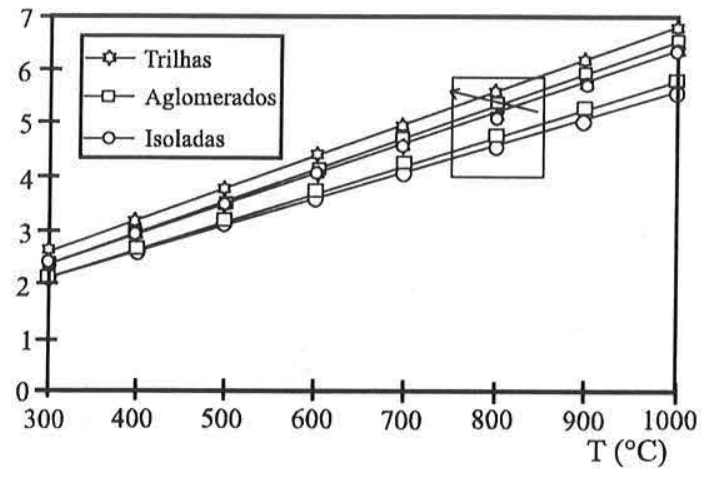

Figura 4 - Isócoras obtidas para inclusões fluidas em cristais de plagioclásio (amostra JRN-37e).

Tabela 2 - Dados usados na determinação das isócoras (JRN66c). Tf and Th são respectivamente temperaturas de fusão $e$ homogeneização de $\mathrm{CO}_{2}$ e d é densidade $\left(\mathrm{g} / \mathrm{cm}^{3}\right)$.

\begin{tabular}{lllllll} 
& \multicolumn{2}{c}{ Trilhas } & \multicolumn{2}{c}{ Aglomerados } & Isoladas \\
\hline JRN-66́ & máx. & mín. & máx. & mín. & máx. & mín. \\
\hline Tf & -58.1 & -58.8 & -58.5 & -58.5 & -58.4 & -58.4 \\
Th & -11.0 & -11.0 & -13.0 & -7.0 & -11.0 & -17.0 \\
D & 0,93 & 0,89 & 0,91 & 0,86 & 0,91 & 0,73 \\
\hline
\end{tabular}

rência, nota-se que ocorre uma pequena quantidade de inclusões.

Os histogramas das Tf e Th (Fig. 9) e os valores da Tabela 3 mostram que, comparativamente à porção félsica, estas inclusões são relativamente mais impuras, mas não apresentam valores muito baixos de Th. Os histogramas contêm dois picos, o que, como no caso da banda félsica (JRN-23b I), pode ser interpretado como resultante de contaminação por fluidos dos metassedimentos.

As isócoras (Fig. 10) mostram que inclusões em trilhas e aglomerados tem curvas similares e as isoladas têm densidades um pouco menores. Isto indica que a sequência cronológica das inclusões até aqui descrita se confirma, apesar de esta amostra (JRN23b) apontar alterações nesta sequência.

Fluidos dos Metassedimentos Estudos petrográficos e microtermométricos de inclusões fluidas foram realizados em cin-
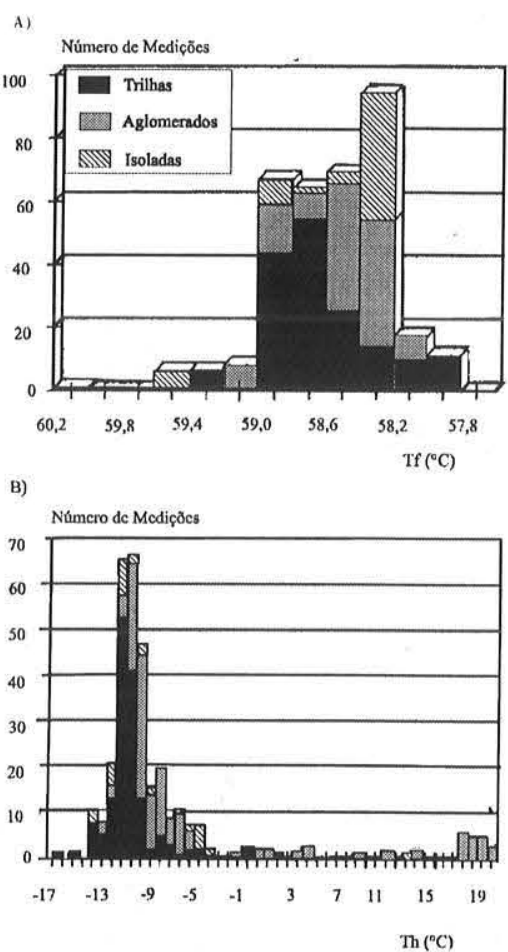

Figura 5 - Histogramas de temperaturas de fusão e homogeneização de $\mathrm{CO}$, para todos os tipos de inclusões (amostra JRN-66c).

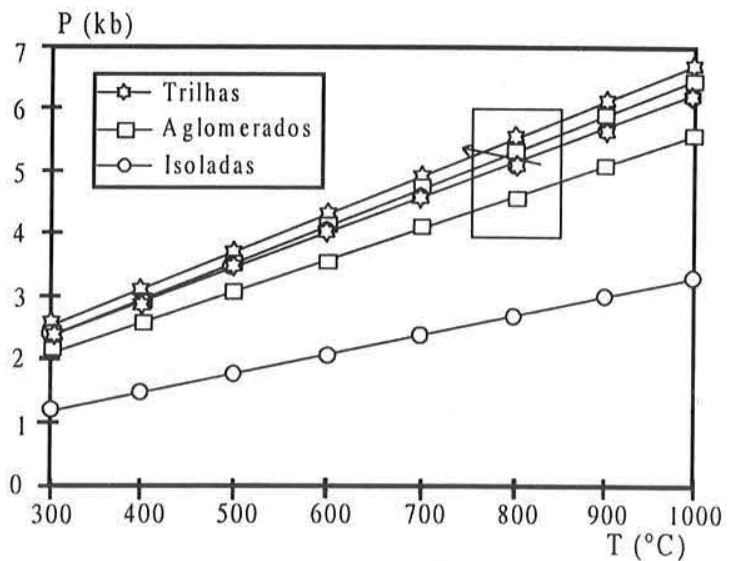

Figura 6 - Isócoras obtidas para inclusões fluidas em cristais de plagioclásio (amostra JRN-66c).

co amostras da sequência metassedimentar do Complexo Juiz de Fora, correlacionável ao Grupo Andrelândia, para analisar inclusões aprisionadas durante o pico metamórfico granulítico do $\mathrm{Ci}$ clo Brasiliano. Foram escolhidas amostras de diferentes eventos deformacionais ocorridos neste ciclo, isto é:

- uma de leucogranito alojada em zona de cisalhamento, associada à fase de deformação $\mathrm{D}_{4}(\mathrm{JRN}-186)$, gerada a partir de fusão parcial de metassedimentos;

- duas de granada-biotita gnaisses com textura blastomilonítica, associados às fases $\mathrm{D}_{2}$ (JRN-107b) e $\mathrm{D}_{3}$ (JRN-127b); 

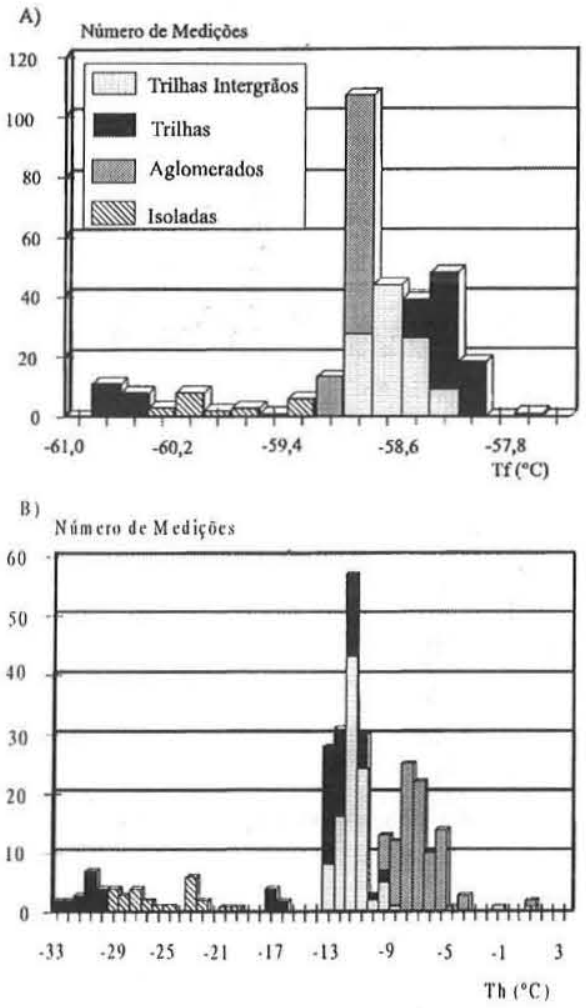

Figura 7 - Histogramas de frequência com Tfe Th para todas as inclusões da amostra JRN-23b I.

- uma de biotita gnaisse ultramilonítico $\left(\mathrm{D}_{2}, \mathrm{JRN}-214\right)$;

- uma de granada-biotita charno-enderbito gerado por fusão parcial de metassedimentos em fácies granulito durante a fase $\mathrm{D}_{2}$ (JRN-223).

Outras duas amostras, da fase $\mathrm{D}_{3}$.foram preparadas, mas apresentaram um número muito reduzido de inclusões para análise. A Tabela 4 mostra a classificação das amostras estudadas e sua relação com a deformação brasiliana.

Assim como nos ortognaisses, os fluidos das inclusões dos metassedimentos são predominantemente constituidos por $\mathrm{CO}_{2}$. Em virtude das temperaturas de fusão situarem-se muito próximo da de fusão do $\mathrm{CO}_{2}$ puro $\left(-56,6^{\circ} \mathrm{C}\right)$, as isócoras foram calculadas considerando-se o fluido como constituido essencialmente por $\mathrm{CO}_{2}$, como proposto por Roeder (1981), quem afirma que para efeito de cálculo de isócoras, inclusões fluidas com temperaturas de fusão com até $-2,0^{\circ} \mathrm{C}$ abaixo de $-56,6^{\circ} \mathrm{C}$ podem ser consideradas como inclusões puras em $\mathrm{CO}_{2}$.

GRANADA-BIOTITA GNAISSE D, - AMOSTRA JRN-107b Esta amostra ocorre em zona de milonitos próxima ao contato entre metassedimentos e ortognaisses situados a sudeste do muscovita quartzito (vide Fig. 1), onde ocorrem granada-biotita gnaisses com lentes félsicas de até $3 \mathrm{~cm}$ com quartzo, feldspato e granada, e que dão à rocha um bandamento tabular paralelo às zonas de cisalhamento geradas durante $\mathrm{D}_{2}$. Os dados microtermométricos foram obtidos em cristais de granada, subordinadamente em plagioclásio e quartzo. A separação dos histogramas por tipos de inclusões não pôde ser feita devido a pequena ocorrência de populações em trilhas e isoladas. A maioria dos dados foram obtidos a partir de

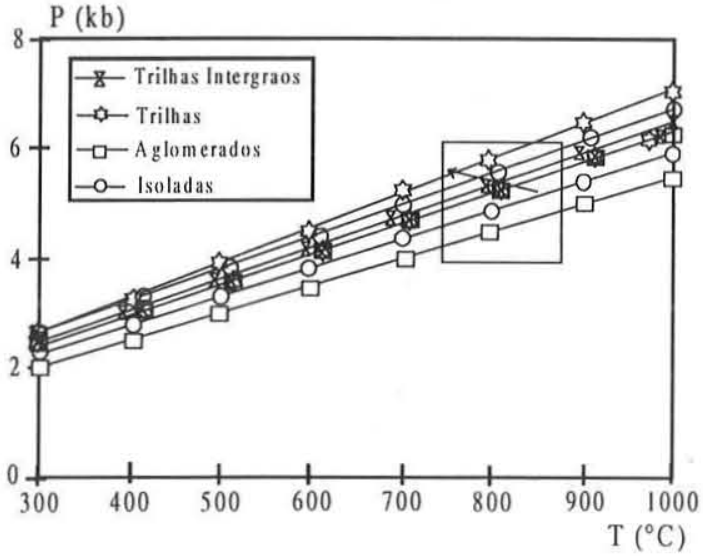

Figura 8 - Isócoras para inclusões fluidas em quartzo e feldspatos da amostra JRN-23b I.
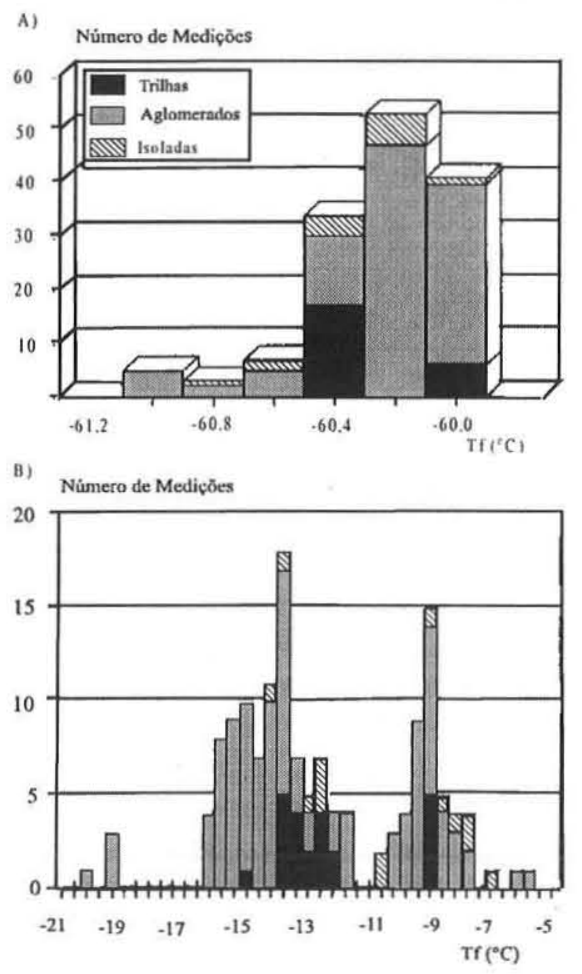

Figura 9 - Histogramas de frequência para Tf e Th (amostra JRN-23b II).

Tabela 3 - Valores utilizados na determinação das isócoras (amostra JRN-23b). Tf and Th são respectivamente temperaturas de fusão e homogeneização de $\mathrm{CO}_{2}$ e dé densidade $\left(\mathrm{g} / \mathrm{cm}^{3}\right)$.

\begin{tabular}{|c|c|c|c|c|c|c|c|c|}
\hline & \multicolumn{2}{|c|}{ Trilhas Intergrăos } & \multicolumn{2}{|c|}{ Trilhas } & \multicolumn{2}{|c|}{ Aglomerados } & \multicolumn{2}{|c|}{ Isoladas } \\
\hline JRN-23b & máx. & $\min$. & Máx. & Min. & máx. & $\min$. & máx. & $\min$. \\
\hline \multicolumn{9}{|c|}{ JRN-23b I } \\
\hline Tf & .58 .9 & -58.9 & -58.4 & .58 .5 & .59 .0 & .59 .0 & -603 & -60.2 \\
\hline Th & -140 & -10.0 & -18.0 & 10 & -10.0 & .6 .0 & -29.0 & -21.0 \\
\hline d & 0,9 & 0,89 & 0,94 & 0.9 & 0.89 & 0,84 & 0.92 & 0,87 \\
\hline \multicolumn{9}{|c|}{ JRN-23b II } \\
\hline Tf & $\cdots$ & $\cdots$ & -60.3 & -60.3 & -60.1 & .60 .1 & -60.2 & -60.2 \\
\hline Th & $\cdots$ & $\cdots$ & -14.0 & -9.0 & -16.0 & .9 .0 & .14 .0 & -8.0 \\
\hline d & ... & ... & 0,85 & 0.79 & 0,86 & 0,79 & 0,83 & 0,78 \\
\hline
\end{tabular}


inclusões dispostas em aglomerados.

Os histogramas de frequência desta amostra (Fig. 11) mostram um pico de temperatura de fusão (Tf) em $-57,7^{\circ} \mathrm{C}$ (11a) e de homogeneização (Th) com dois picos, um em $-28^{\circ} \mathrm{C}$ e o outro em torno de $-16^{\circ} \mathrm{C}$ (Fig. 1lb). Os dados para as isócoras desta amostra e das demais constam da Tabela 5.

Visto que as medidas de temperaturas de mudanças de fase nesta amostra foram obtidas a partir de inclusões fluidas hospedadas em granada pré a sin- $\mathrm{D}_{2}$, é possível afirmar que estes dados provavelmente refletem condições de aprisionamento de fluidos durante o pico metamórfico Brasiliano. A alta densidade dos fluidos (de 1.07 a $\left.1.00 \mathrm{~g} / \mathrm{cm}^{3}\right)$ está representada na figura 12 pelas isócoras \#1 e \#2, respectivamente de densidades máxima e mínima nesta amostra. O campo intermediário entre ambas curvas intersecta quase que totalmente o campo de pico metamórfico granulítico Brasiliano e a intersecção destes dois deve ser considerada como representativa dos intervalos de pressão e temperaturas de aprisionamento $\left(6-7 \mathrm{~kb} ; 750-800^{\circ} \mathrm{C}\right)$ destas inclusões.

GRANADA-BIOTITA CHARNOENDERBITO D - AMOSTRA JRN223 Rochas de composição charnockítica a charno-enderbítica comumente se associam à fusão parcial de granada-biotita gnaisses aflorantes a norte da faixa ultramilonítica (Fig. 1). Esta amostra foi coletada em uma lente granulítica, com foliação interna paralela às zonas de cisalhamento da fase de deformação $\mathrm{D}_{2}$. A amostra é composta por plagioclásio, biotita, quartzo, K-felfdspato, granada, ortoclinopiroxênio, clinopiroxênio e zircão. Os dados foram obtidos a partir de medidas feitas em cristais de feldspatos e quartzo. A exemplo da amostra JRN-107b, esta apresentou populações de inclusões predominantemente em aglomerados (Fig. 13) e seus histogramas também não puderam ser diferenciados por categoria de inclusões.

As temperaturas de fusão e homogeneização (Fig. 11) possuem um pico de $\mathrm{Tf}$ em $-57,7^{\circ} \mathrm{C}$, com Thentre $-18,5 \mathrm{e}-16,0^{\circ} \mathrm{C}$. As isócoras máxima e mínima ( Tabela 5) estão representadas na figura 12 (curvas \#3 e \#4, respectivamente) e o campo de densidade das inclusões também cruza a faixa de pico metamórfico. Portanto, o campo de densidades de inclusões aprisionadas durante $\mathrm{D}_{2}$ pode ser entendido como intermediário entre as isócoras \#1 e \#2, contido no campo de pico metamórfico.

SILLIMANITA-GRANADA-BIOTITA GNAISSE D - AMOSTRA $J R N-127 b$ Esta amostra tem textura blastomilonítica e é constituida por quartzo, plagioclásio, biotita, granada, K-feldspato, sillimanita e muscovita. Ocorre em região próxima ao contato com os ortognaisses e possui bandamento composicional com mergulho sub-vertical para norte, interpretado como gerado durante a tectônica direcional associada à fase $\mathrm{D}_{3}$. As temperaturas de mudanças de fase foram medidas em cristais de quartzo e plagioclásio, em inclusões dispostas em aglomerados e raras isoladas.

Os histogramas mostraram um pico de temperaturas de fusão

Tabela 4 - Relação entre os litotipos analisados e a deformação brasiliana.

\begin{tabular}{ccc}
\hline$N^{\circ}$ da Amostra & Rocha & Fase de Deformação \\
\hline JRN-107b & Granada-biotita gnaisse & $\mathrm{D}_{2}$ \\
JRN-223 & Granada-biotita chamo-enderbito & $\mathrm{D}_{2}$ \\
JRN-127b & Sillimanita-gr-bi gnaisse & $\mathrm{D}_{3}$ \\
JRN-186 & Biotita leucogranito & $\mathrm{D}_{4}$ \\
JRN-214 & Biotita gnaisse ultramilonítico & $\mathrm{D}(?)$ \\
\hline
\end{tabular}

$$
\mathrm{P}(\mathrm{kb})
$$

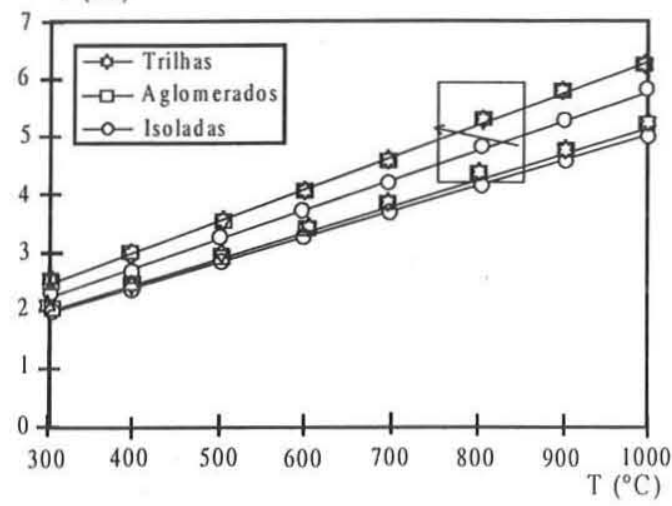

Figura 10 - Isócoras obtidas para as inclusões fluidas da amostra $J R N-23 b$ II, aprisionadas principalmente em cristais de plagioclásio.

em $-58,5^{\circ} \mathrm{C}$ (Fig. 14a), com temperaturas de homogeneização entre $-22,0^{\circ} \mathrm{Ce}-12,0^{\circ} \mathrm{C}$ (Fig. 14b). Estes dados resultam em isócoras de alta densidade, de 1,038 a 0,994 g/ $\mathrm{cm}^{3}$ (Tabela 5), representadas na figura 12 pelas curvas \#5 e \#6. Pode-se observar que o campo de abrangência de densidades associadas à fase $\mathrm{D}_{3}$, situado entre ambas curvas, é parcialmente intersectado pelo campo de pico metamórfico, e este superpõe-se ao delimitado para a fase $\mathrm{D}_{2}$, ainda que evidenciando densidades mais baixas.

BIOTITA LEUCOGRANITO D 4 - AMOSTRA JRN-I86 Esta amostra foi coletada em um stock gerado por fusão parcial de metassedimentos, em zona de cisalhamento desenvolvida durante a fase $\mathrm{D}_{4}$ (Fig. 1). Em seção bipolida apresenta alta população de inclusões em aglomerados, mas um grande número de inclusões em trilhas (Fig. 15) pôde também ser analisada, o que permitiu a confecção de histogramas diferenciados para cada tipo de inclusões. Os dados de inclusões isoladas (Fig. 16) são, porém, escassos e foram incluidos no grupos dos aglomerados. As medições foram realizadas em cristais de feldspatos e algumas em quartzo.

Os histogramas de frequência constam das figuras 17a e 17b. $\mathrm{Na}$ figura 17a observa-se dois picos de temperaturas de fusão diferentes de inclusões em trilhas e aglomerados, respectivamente $-56,7^{\circ} \mathrm{Ce}-57,7^{\circ} \mathrm{C}$. A figura $17 \mathrm{~b}$ mostra que as temperaturas de homogeneização de inclusões em trilhas varia entre $-6,0$ e $2,0^{\circ} \mathrm{C}$, e das em aglomerados entre $-9,4 \mathrm{e}-0,6^{\circ} \mathrm{C}$.

As isócoras das inclusões em aglomerados estão representadas, na figura 12, pelas curvas \#7 e \#8 e para as em trilhas pelas curvas \#9 e \#10 (dados na Tabela 5). Estas isócoras, que correspondem às densidades de inclusões aprisionadas durante a fase $\mathrm{D}_{4}$, dispõem-se abaixo das isócoras das inclusões das fases $\mathrm{D}_{2}$ e $\mathrm{D}_{3}$, não chegando a cruzar o campo de pico metamórfico.

É importante notar que o padrão detectado nos ortognaisses, onde inclusões secundárias apresentam densidades maiores do que as primárias, se inverte nos metassedimentos e o campo de densidades de inclusões em trilhas, localizado entre as curvas \#9 e \#10, situa-se abaixo do campo de inclusões em aglomerados (curvas \#7 e\#8; Fig. 12).

BIOTITA GNAISSE ULTRALILONÍTICO $D_{2}-D_{3}$ (?) - AMOSTRA $J R N-214$ Esta amostra é constituída por quartzo, plagioclásio, biotita, muscovita, K-feldspato, minerais opacos, carbonato e lo- 
A)

Número de Medidas

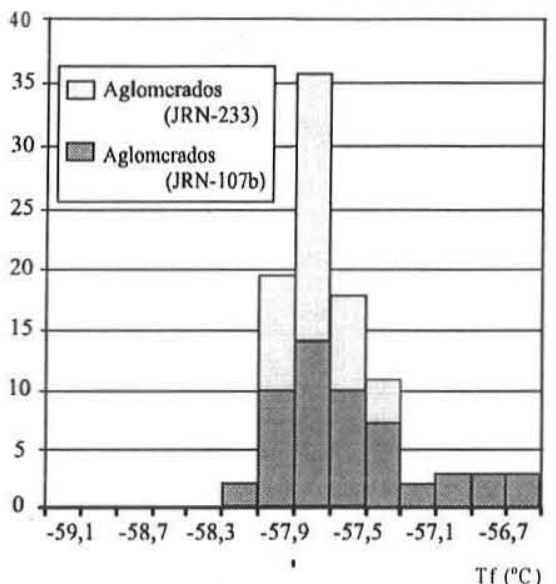

B)

Número de Medições

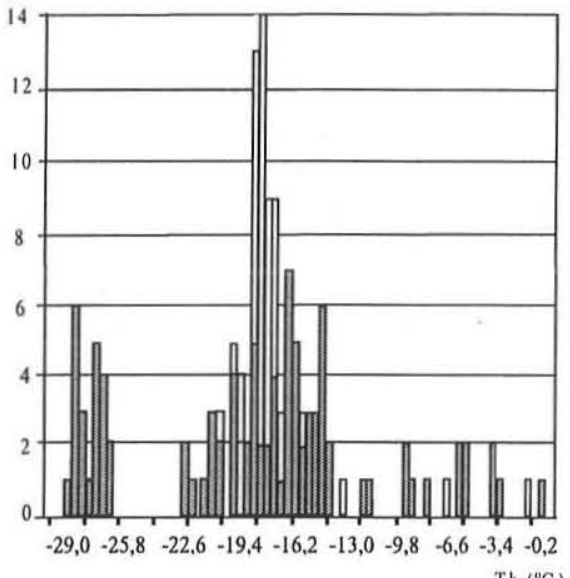

Figura 11 - Histogramas de frequência de temperaturas de fusão (a) e homogeneização (b) de inclusões em aglomerados das amostras JRN-107b e JRN-223, associadas à fase $D_{2}$ de deformação.

Tabela 5 - Valores usados na obtenção das isócoras para amostras de metassedimentos. Tf and Th são respectivamente temperaturas de fusão e homogeneização de $\mathrm{CO}_{2}$ e dé densidade $\left(\mathrm{g} / \mathrm{cm}^{3}\right)$.

\begin{tabular}{|c|c|c|c|c|c|c|c|c|c|c|c|c|c|c|c|c|}
\hline \multirow{3}{*}{ Tipo } & \multicolumn{2}{|c|}{ JRN-107b } & \multirow{2}{*}{\multicolumn{2}{|c|}{$\frac{\text { JRN-223 }}{\text { aglomerados }}$}} & \multirow{2}{*}{\multicolumn{2}{|c|}{$\begin{array}{c}\text { JRN-186 } \\
\text { aglomerados }\end{array}$}} & \multicolumn{4}{|c|}{ JRN-186 } & \multicolumn{4}{|c|}{ JRN-186 } & \multirow{2}{*}{\multicolumn{2}{|c|}{$\begin{array}{l}\text { JRN-214 } \\
\text { isoladas }\end{array}$}} \\
\hline & aglor & rados & & & & & \multicolumn{2}{|c|}{ trilhas } & \multicolumn{2}{|c|}{ aglomerados } & \multicolumn{2}{|c|}{ trilhas } & \multicolumn{2}{|c|}{ aglomerados } & & \\
\hline & máx & $\min$ & máx & min & $\operatorname{máx}$ & $\min$ & máx & min & $\operatorname{máx}$ & $\min$ & máx & $\min$ & máx & min & máx & min \\
\hline Tf & -57.7 & -57.7 & -57.7 & -57.7 & -58.5 & -58.5 & -56.7 & -56.7 & -57.7 & -57.7 & -58.1 & -58.1 & -56.9 & -56.9 & -56.8 & -56.8 \\
\hline Th & -28.0 & -13.0 & -18.5 & -16.0 & -22.0 & -12.0 & -9.4 & -0.6 & -6.0 & 2.0 & 12.6 & 18.2 & 10.6 & 20.0 & 26.6 & 28.2 \\
\hline d & 1,068 & 0,999 & 1,025 & 1,014 & 1,038 & 0,994 & 0,962 & 0,916 & 0,980 & 0,932 & 0,842 & 0,793 & 0,857 & 0,774 & 0,685 & 0,652 \\
\hline
\end{tabular}

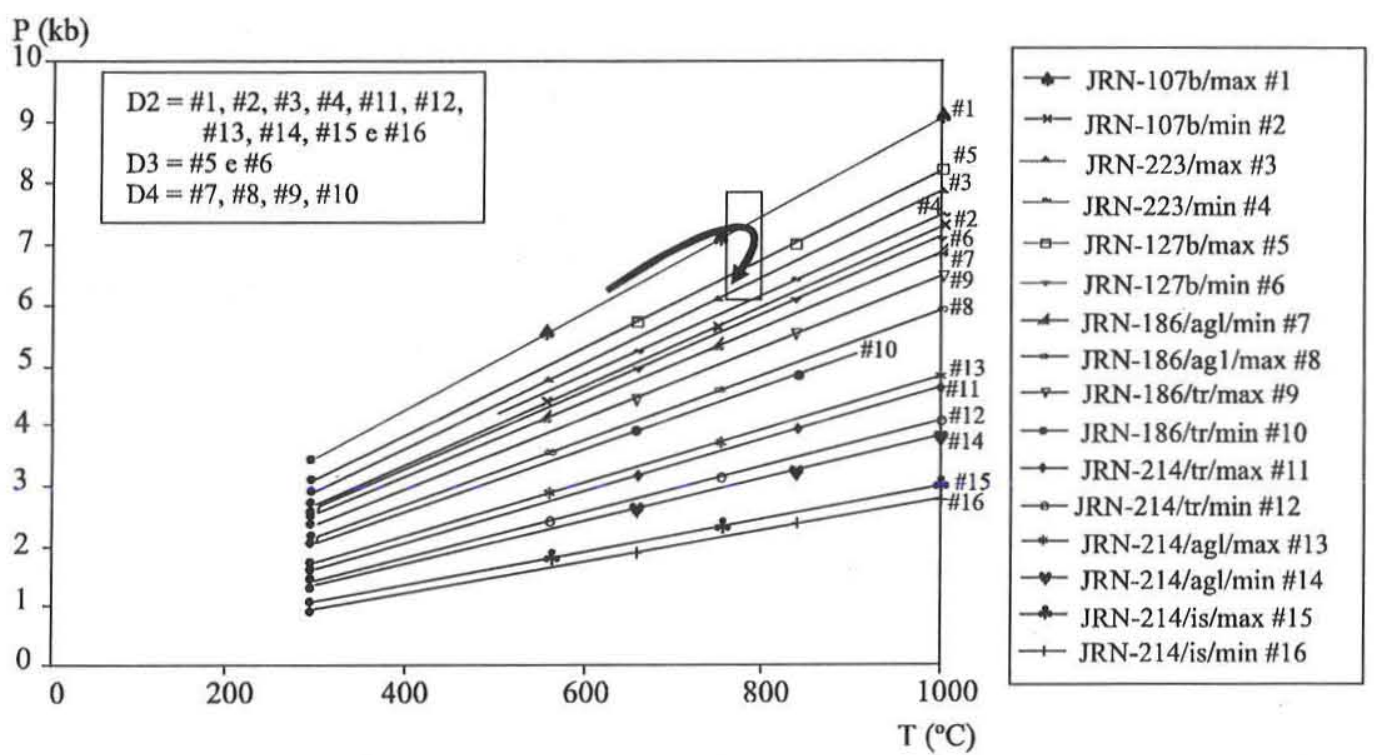

Figura 12 - Gráfico P-T mostrando a posição das isócoras obtidas para inclusões fluidas da sequência metassedimentar do Domínio Tectônico Juiz de Fora, separadas de acordo com as fases de deformação brasilianas, e também quanto ao tipo de inclusão. $O$ retângulo indica o campo de pico metamórfico granulítico do Evento Brasiliano, e a curva orientada o provável caminho retrometamórfico sofrido (ver discussão no texto). Abreviações: \#n, aponta o posicionamento exato de cada isócora; tr, agl e is, representam isócoras obtidas para inclusões em trilhas, aglomerados e isoladas, respectivamente; $D_{2}, D_{3}$, e $D_{4}$, as fases deformacionais brasilianas as quais estão associadas as amostras; e junto à sigla JRN o número da amostra estudada. 


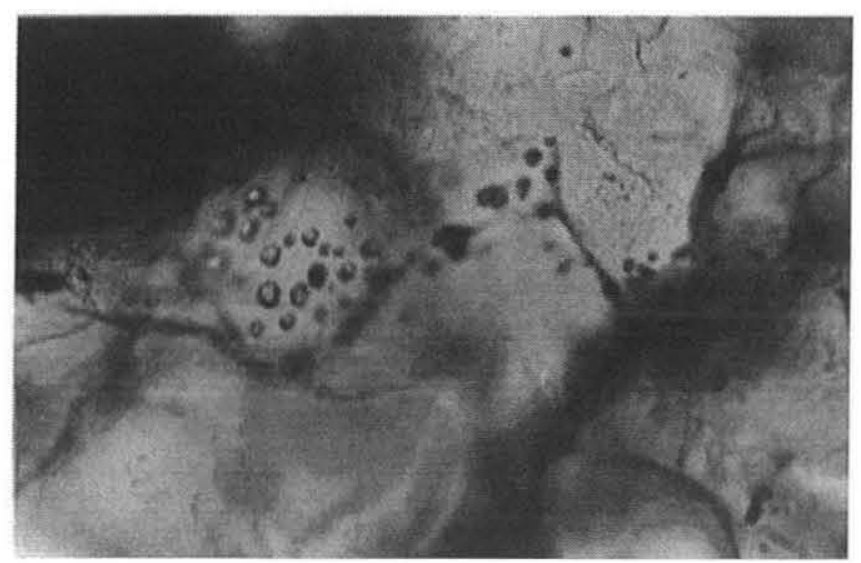

Figura 13 - Grupos de inclusões ricas em $\mathrm{CO}_{2}$, em aglomerados em cristal de quartzo de enderbito (amostra JRN-223) associado aos metassedimentos em fácies granulito. Comprimento maior da foto $=35$.

calmente clorita. Na área estudada esta faixa possui mergulhos médios para norte e associa-se a estruturas amendoadas. Entretanto, é possível que esta faixa tenha sido constantemente reativada durante a evolução final do Cinturão Ribeira. Nesta amostra, os dados de inclusões foram obtidos em cristais de plagioclásio e quartzo e puderam ser individualizadas por tipos diferentes representados separadamente nos histogramas.

Os histogramas (Fig. 18) e os dados correspondentes (Tabela 5) destacam dois picos de temperaturas de fusão em inclusões em aglomerados que entretanto não resultam em mudanças drásticas ou coerentes nas temperaturas de homogeneização. A configuração das isócoras (Fig. 12) revelou curvas de densidades moderadas a baixas $\left(0,857\right.$ e $\left.0,652 \mathrm{~g} / \mathrm{cm}^{3}\right)$, afastadas do campo de pico metamórfico.

Apesar de este ultramilonito estar associado à estrutura amendoada gerada nos estágios finais da fase $\mathrm{D}_{2}$, os dados de inclusões fluidas sugerem que esta estrutura se manteve ativa durante um período de tempo maior, na medida que não há valores coerentes com os do pico metamórfico. A recristalização impediu que inclusões geradas durante este pico fossem preservadas.

Em relação à cronologia destas inclusões, as em aglomerados possuem densidades maiores do que em trilhas, mas as isoladas possuem as densidades mais baixas. O reduzido número de inclusões isoladas, aliado a intensa recristalização não permite considerações consistentes.

DISCUSSÃODOSRESULTADOSECONCLUSÕES Astemperaturas de fusão, quando confrontadas com as de homogeneização em uma determinada amostra, algumas vezes evidenciam um comportamento segundoo qual, para a mesma temperatura de fusão (mesma composição), ocorrem diferentes temperaturas de homogeneização. Isto mostra que os valores de temperaturas de homogeneização (densidade) nem sempre variam em função da composição, sendo esta variação provavelmente devido a processos posteriores ao pico metamórfico granulítico. Não necessariamente, as inclusões com temperaturas de homogeneização menores (maiores densidades) são de pico metamórfico, mas provavelmente representam inclusões formadas mais próximas do pico.

As inclusões estudadas ssão típicas de fácies granulito, pos-
(A)

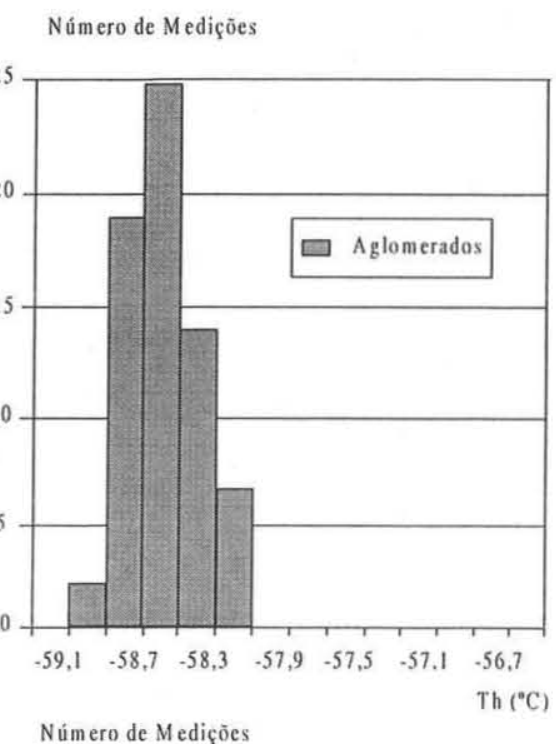

(B)

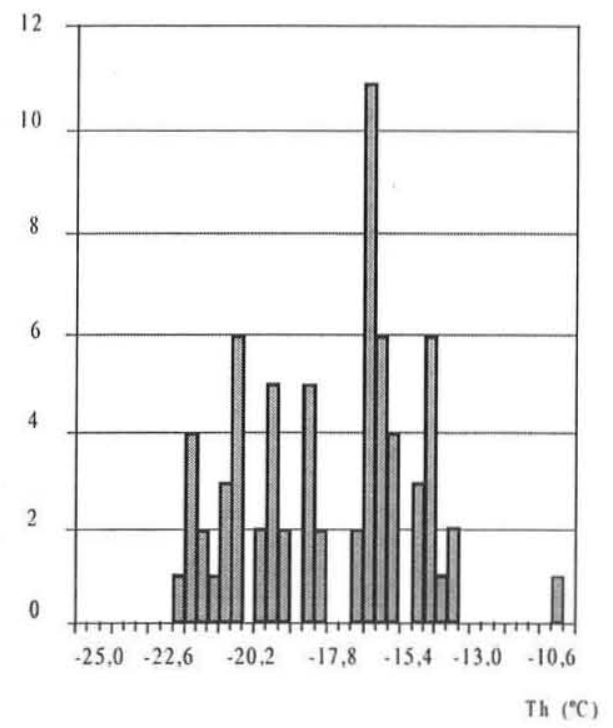

Figura 14 - Temperaturas de fusão (a) e homogeneização (b) de inclusões em aglomerados da amostra JRN-127b, representativa da deformação $D_{3}$.

suindo, nas rochas do embasamento, de 81 a $93 \%$ de $\mathrm{CO}_{2}$, com densidades moderadas, entre 0,79 e $0,94 \mathrm{~g} / \mathrm{cm}^{3}$, e para a porção metassedimentar, de 92 a $100 \%$ de $\mathrm{CO}_{2}$, e densidades moderadas a altas, entre 0,92 e $1,07 \mathrm{~g} / \mathrm{cm}^{3}$. Exceção deve ser feita à amostra de ultramilonito (JRN-214) que apresenta associação mineral compatível com metamorfismo da fácies xisto-verde a anfibolito e que gerou inclusões de baixa densidade possivelmente devido a reativações tardias, de temperatura em torno de $450^{\circ} \mathrm{C}$. Portanto, ao contrário do que poderia se esperar, a geração de textura ultramilonítica ocorreu em regiões mais rasas do orógeno, possivelmente devido a um rápido soerguimento (vide Fig. 19).

De um modo geral, as inclusões fluidas das rochas metassedimentares (Grupo Andrelândia), mostraram densidades mais elevadas e composições mais ricas em $\mathrm{CO}_{2}$, comparativamente aos granulitos ortoderivados. 


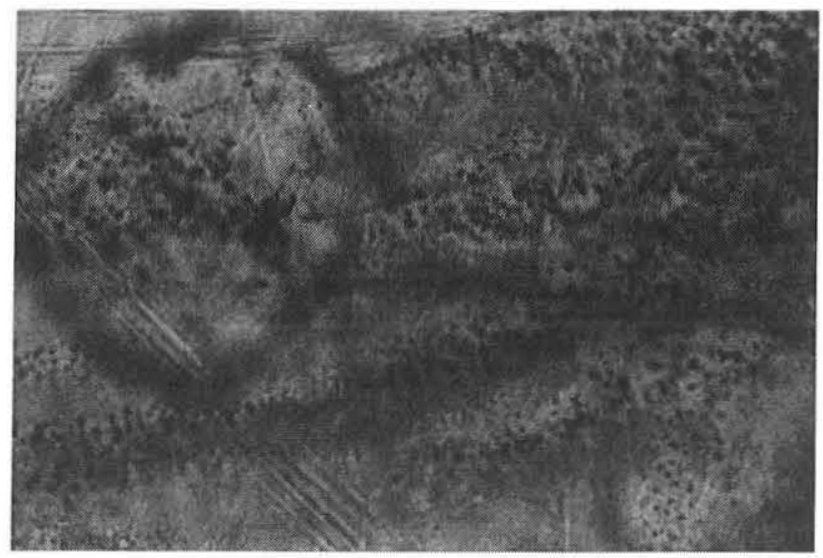

Figura 15 - Inclusões em trilhas, ricas em $\mathrm{CO}_{2}$, em cristal de feldspato, em "stock" leucogranodiorítico (amostra JRN-186). Notar outra direção de trilha no lado direito da foto. Os dados microtermométricos em ambas as direções são semelhantes. Comprimento maior da foto $=70$ ?

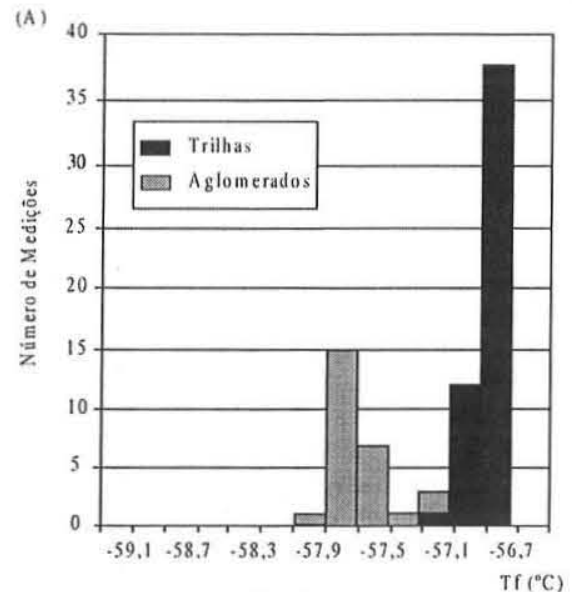

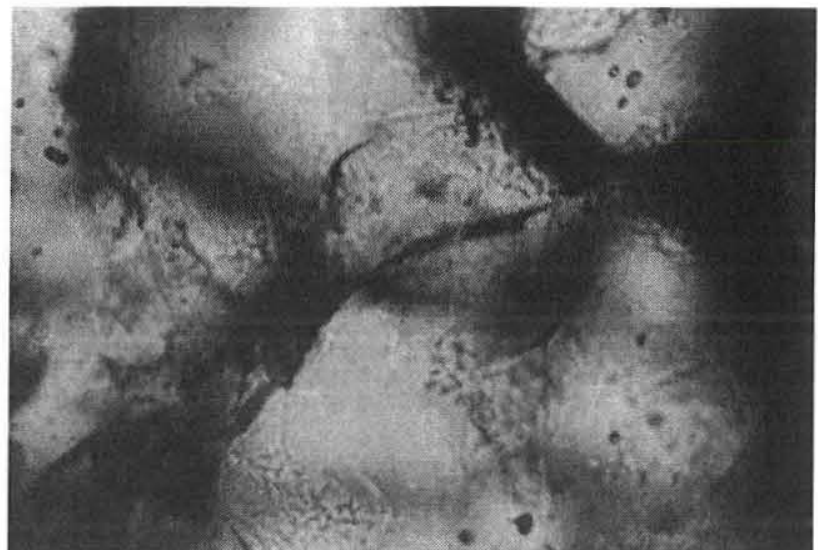

Figura 16 - Região de inclusões de $\mathrm{CO}_{2}$ isoladas, em cristal de quartzo no mesmo leucogranodiorito da fotomicrografia anterior $(J R N-186)$. Comprimento maior da foto $=35$ ?.

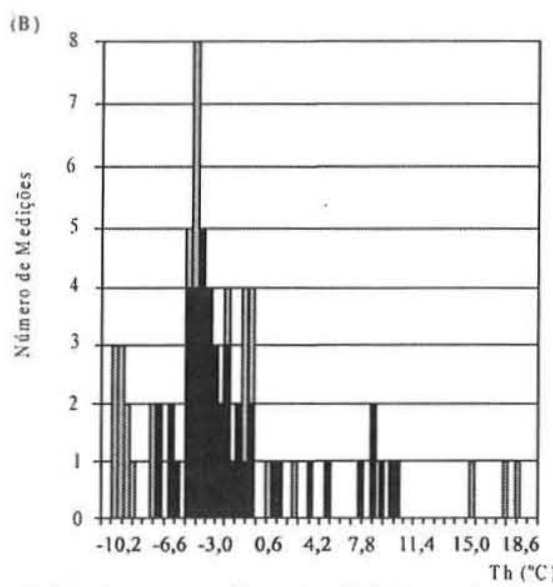

Figura 17 - Diagramas de frequência das temperaturas de fusão (a) e homogeneização (b) de inclusões fluidas diferenciadas por ocorrência em trilhas ou em aglomerados na amostra JRN-186, relacionada a fase $D_{4}$.

Os fluidos associados aos ortognaisses revelaram, pela cronologia relativa das inclusões estudadas, que as últimas inclusões formadas (em trilhas) possuem sistematicamente densidades maiores do que as primeiras (isoladas), o que sinaliza um caminho retrometamórfico anti-horário durante o Evento Transamazônico, com resfriamento aproximadamente isobárico, representado pelas setas nos diagramas das figuras 3,4,6,8 e 10. Estas figuras apresentam a configuração das isócoras de inclusões em ortogranulitos, correspondentes às menores e maiores densidades, as quais intersectam o retângulo do provável pico metamórfico das rochas do embasamento. $\mathrm{O}$ intervalos de pressão e temperatura destas situa-se respectivamente entre 4 a $6 \mathrm{~Kb}$ e 750 e $850^{\circ} \mathrm{C}$.

As setas nos gráficos representam um segmento do caminho retrometamórfico. Esta determinação foi feita com base na cronologia das inclusões estudadas, onde as últimas inclusões (trilhas) apresentam sistematicamente densidades maiores.

O estudo de inclusões fluidas em rochas supracrustais do Grupo Andrelândia, metamorfisadas em fácies granulito, mostrou que as aprisionadas na fase $D_{2}$, correspondente ao pico metamórfico brasiliano, possuem densidades mais elevadas do que as da fase $\mathrm{D}_{3}$, que por sua vez possuem densidades maiores do que as da fase $\mathrm{D}_{4}$. A figura 19 mostra que somente as inclusões fluidas associadas às fases $\mathrm{D}_{2} \mathrm{e}_{3}$ cortam o campo de pico metamórfico brasiliano, estabelecido entre 6 e $8 \mathrm{kbe} 750 \mathrm{e} 800^{\circ} \mathrm{C}$.

A curva orientada nesta figura representa o provável caminho P-T-t, definida com base no padrão de diminuição progressiva das densidades das inclusões (das amostras associadas à fase $\mathrm{D}_{2}$ até a $\left.\mathrm{D}_{4}\right)$, aliado ao fato de inclusões em aglomerados apresentarem densidades maiores do que aquelas em trilhas. Isto aponta para uma diminuição de pressão mais significativa do que a de temperatura após o pico metamórfico, configurando uma descompressão aproximadamente isotérmica, com um caminho P-T-t horário.

Harley (1989), por compilação do caminho retrometamórfico de vários terrenos granulíticos do mundo, estipulou os caminhos P-T mais comuns para as rochas granulíticas. A divisão entre granulitos de resfriamento isobárico, do tipo IBC (isobaric cooling), e de descompressão isotérmica, tipo ITD (isothermal decompression), é largamente usada para terrenos granulíticos. Bohlen (1991) propõe que o caminho do tipo IBC em granulitos seja causado por underplating magmático abaixo de uma crosta continen- 

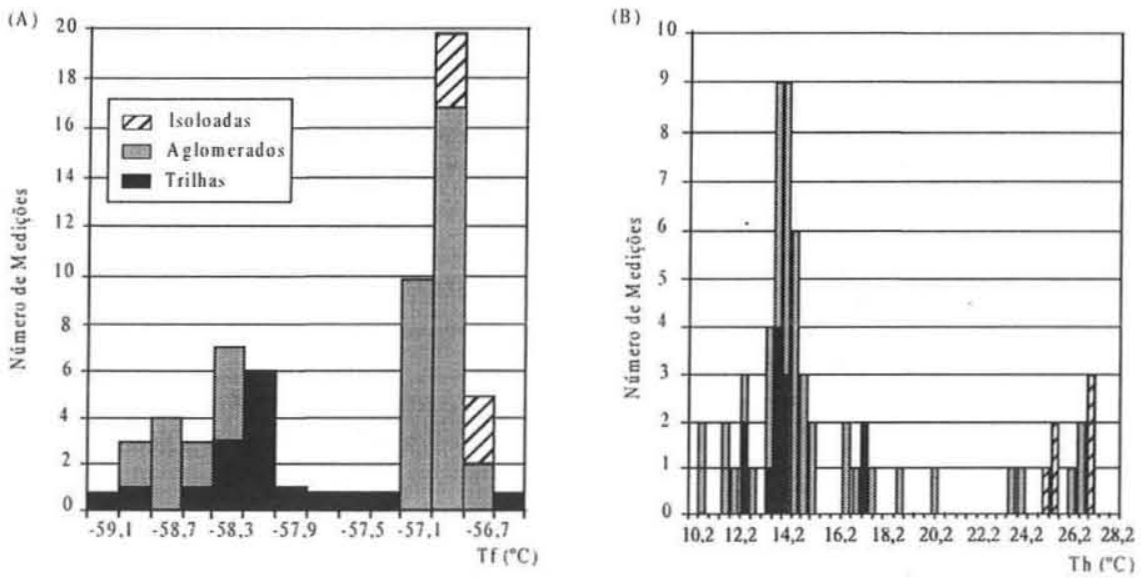

Figura 18 - Histogramas de frequência com distribuição das temperaturas de fusão (a) e homogeneização(b) de inclusões subdivididas em trilhas, aglomerados e isoladas para a amostra JRN-214.

tal existente, com intrusão e cristalização de substanciais volumes de materiais ígneos dentro da crosta. Um ambiente de arco magmático continental foi proposto como sendo um provável regime tectônico no qual tais processos poderiam ocorrer; porém "hot spots" ou ambientes de rifts incipientes (Sandiford \& Powell 1986) em certas circunstâncias podem também levar a caminhos anti-horários do tipo IBC. Segundo Harley (1989), granulitos ITD são formados em crosta espessada por colisão, com adições magmáticas como uma importante fonte de calor.

Os dados geológicos existentes (Nogueira \& Choudhuri 2000,
Nogueira 1999, Duarte 1998) e de inclusões fluidas apresentados e gravados nos domínios estruturais onde predominam rochas do embasamento, indicam a existência de uma complexa evolução dos processos geológicos ocorridos previamente ao Evento Brasiliano e o metamorfismo de fácies granulito pode estar relacionadas a um evento tectônico extensional Transamazônico, com a formação de intra e underplating magmático, provendo fluidos ricos em $\mathrm{CO}_{2}$ e excesso de calor necessário ao metamorfismo granulítico mais antigo.

Neste processo contínuo, a intrusão de consideráveis volumes

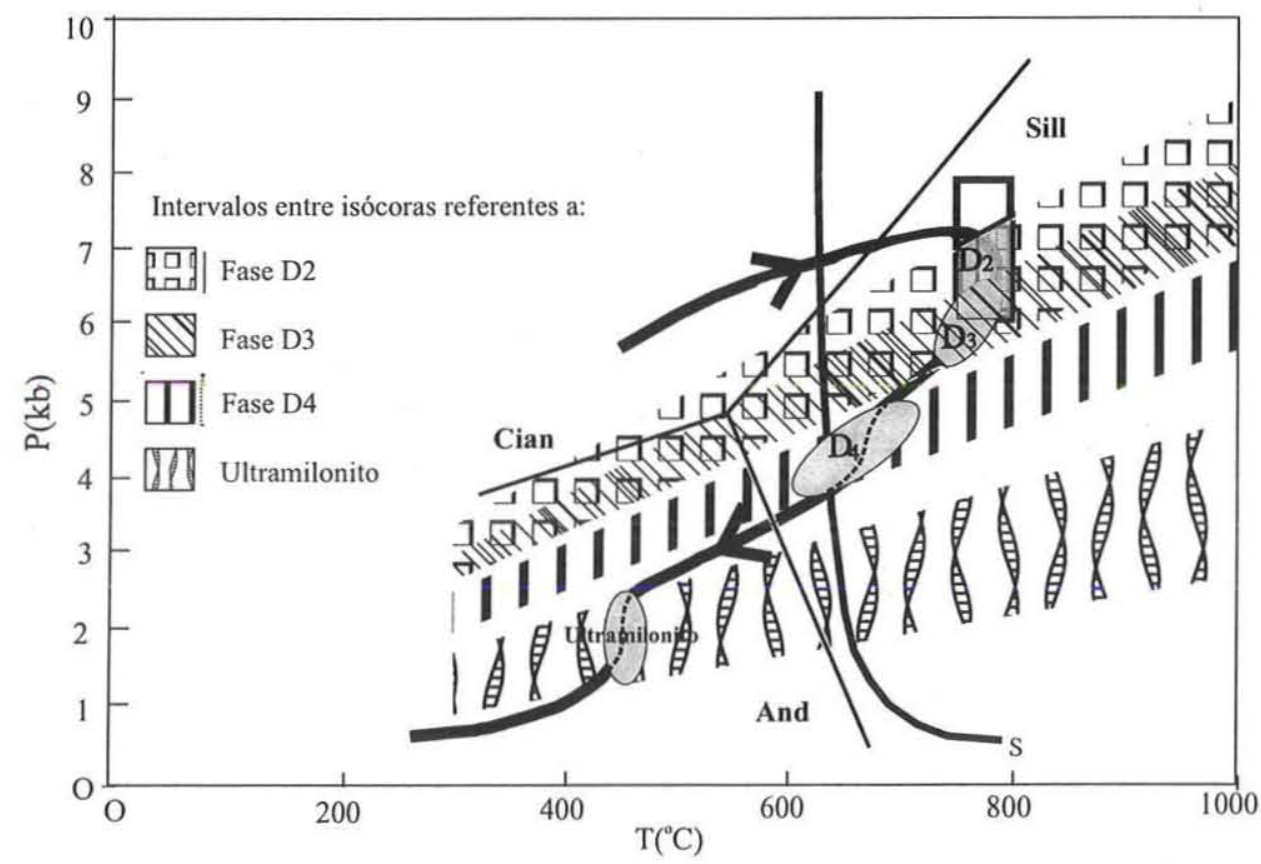

Figura 19 - Diagrama P-T mostrando os intervalos entre isócoras de inclusões fluidas aprisionadas durante o Evento Brasiliano. A seta orientada indica a provável trajetória P-T-t e os campos em cinza as condições metamórficas de cada fase de deformação brasiliana e de geração do biotita ultramilonito. Notar a queda de pressão associada a este último estágio e à fase D4, relacionada à zonas de cisalhamento dúcteis distensivas. Cian, And e Sill representam os campos de estabilidade de cianita, andalusita $e$ sillimanita respectivamente. S indica a posição da curva solidus para líquido granítico no sistema quartzo-albita-ortoclásio em presença de água, segundo Winkler (1967). 
de magmas básicos na base e dentro da crosta inferior causaria um forte aumento no fluxo térmico, propiciando o início de fusão parcial de rochas da crosta inferior, possivelmente de composição mais básica, e gerando uma grande quantidade de magmas de composição provável tonalítica a granítica. Processos de fusão parcial e diferenciação nestas condições retirariam grande quantidade de $\mathrm{H}_{2} \mathrm{O}$ do sistema e, aliado a entrada de fluidos ricos em $\mathrm{CO}_{2}$ provenientes das rochas máficas, causaria metamorfismo granulítico extensivo nos ortognaisses do embasamento.

Durante o Evento Brasiliano, o processo colisional, gerou zonas de cisalhamento e empurrões que colocaram em um mesmo nível crustal rochas supracrustais e o embasamento granulítico (Complexo Juiz de Fora). Esta colisão se iniciou com vergência de SE para NW, em direção ao Cráton do São Francisco, gerando nos estágios sin-colisionais estruturas anastomosadas ou em amêndoas, relacionadas a fase direcional da deformação. Neste período, intensos processos anatéticos geraram nos metassedimentos uma grande quantidade de migmatitos e rochas graníticas e charnockíticas. Estes processos de fusão parcial possivelmente retiraram grandes quantidades de $\mathrm{H}_{2} \mathrm{O}$ do sistema, fazendo com que os metassedimentos atingissem a fácies granulito, resultando no metamorfismo granulítico Brasiliano, com temperaturas máximas de $800^{\circ} \mathrm{C}$ e pressões entre 6 e $7 \mathrm{~kb}$.

Agradecimentos Ao apoio financeiro da FAPESP (Proc. 94/ 3023) e do CNPq (Proc. 420097/01-05). Ao Dailto Silva, Técnico do Laboratório de Inclusões Fluidas do IG/UNICAMP. Aos revisores da RBG pelas sugestões ao manuscrito.

\section{Referências}

Bohlen S.R. 1991. On the formation of granulites. J. Metamorphic Geol., 9:223-229.

Brown P.E. 1989. FLINCOR: A fluid inclusion data reduction and explotation program (abstract). Second Biennial Pan-American Conf. of Research on Fluid inclusions Progr. with abstract, 14.

Brown P.E. \& Lamb W.M. 1989. P-V-T properties of fluids in the system $\mathrm{H}_{2} \mathrm{O}-\mathrm{CO}_{2}-\mathrm{NaCl}$ : New graphical presentations and implications for fluid inclusion studies. Geochim. Cosmochim. Acta, 53, (in press).

Duarte B.P. 1998. Evolução tectônica dos ortognaisses dos complexos Juiz de Fora e Mantiqueira na região de Juiz de Fora: geologia, petrologia e geoquímica. Tese de Doutoramento, IG/USP, 268p.

Duarte B.P., Nogueira J.R., Heilbron M., Figueiredo M.C.H. 1994. Geologia da região de Juiz de Fora e Matias Barbosa (MG). SBG, Congr. Bras. Geol., 38, Camboriú, Resumos Expandidos, 2:88-90.

Haarley S.L. 1989. The origins of granulites: a metamorphic perspective. Geol. Mag., 126:215-247.

Heilbron M., Rocha A.D., Silva L.G.E., Nogueira J.R., Trouw R.A.J., Polônia J.A.L. 1994a Compartimentação tectônica da seção Conceição do Ibitipoca (MG)-Valença (RJ), segmento central da Faixa Ribeira. In: SBG, Congr. Bras. Geol., 38, Camboriú, Resumos Expandidos, 2:55-56.

Heyen G., Ramboz C., Dubessy J. 1982. Simulation des equilibres de phases dans le systeme $\mathrm{CO}_{2}-\mathrm{CH}_{4}$, en dessous de $50 \mathrm{C}$ et de 100 bar. Application aux inclusios fluides. C.R. Acad. Sc. Paris, t.294, serie II, 203-206.

Kerrkhof van Den A.M. 1990. Isochoric phase diagams in the systems $\mathrm{CO} 2-\mathrm{CH} 4$ and $\mathrm{CO} 2-\mathrm{N} 2:$ Aplication to fluid inclusions. Geoch. Cosmoch. Acta, 54:621-629.

Lamb W.M., Valley J.W., Brown P.E. 1987. Post metamorphic CO2-rich fluid inclusions in granulites. Contrib. Mineral. Petrol.,96:485-495.

Machado N., Valladares C.S., Heilbron M., Valeriano C. 1996. U-Pb geochronology of the central Ribeira belt (Brazil) and implications for the evolution of the Brazilian Orogeny. Prec. Res., 79:347-362.

Nogueira J.R. \& Choudhuri A. 2000. Geotectonic models and geologic evolution of the high-grade gneiss terranes of Juiz de Fora (MG), Brazil. Rev. Bras. Ceoc., 30:169-173.

Nogueira J.R. 1999. Evolução geológica dos terrenos de alto grau metamórfico da Faixa Ribeira na região de Juiz de Fora, Minas Gerais. Tese de Doutorado. IG/UNICAMP, 190p.

Nogueira J.R. 1994. Relações tectono-estruturais e metamórficas entre metassedimentos e ortognaisses em fácies granulito na região a sudoeste de Juiz de Fora, Minas Gerais. Dissertação de Mestrado, DG/UFRJ, 187p.

Ribeiro A., Trouw R.A.J., Andreis R., Paciullo F.P., Valença J.G. 1995. Evolução das bacias proterozóicas e o termo-tectonismo brasiliano na margem sul do Cráton do São Francisco. Rev. Bras. Geoc., 25:235-248.

Roedder E. 1981. Origin of fluid inclusions and changes that occur after trapping. In: L.S. Hollister \& M.L. McCrawford (Eds.) Fluid Inclusion: Aplications to petrology; Mineralogical Society of Canada, Short Course Handbook, 6:101-128.

Sandiford M.A. \& Powell R. 1986. Deep crustal metamorphism during continental extension; ancient and modern examples. Earth and Planet. Sci Letters, 79:151-158.

Sheperd T.J., Rankin A.H., Alderton P.H.M. 1985. A pratical guide to fluid inclusion studies. Ed. Blackie, 239p.

Swanenberg H.E.C. 1979. Phase equilibria in carbonic systems, and their application to freezing studies of fluid inclusions. Contrib. Mineral. Petrol., 68:303-306.

Touret J.L.R. 1971. Le facies granulite en Norvege meridionale. II: Les inclusions fluides. Lithos, 4:423-436.

Winkler H.G.F. 1967. Petrogenesis of metamorfic rocks. Springer-Verlag. New York Inc.

Manuscrito A-1423

Recebido em 21 de março de 2003 Revisão dos autores em 15 de junho de 2004 Revisão aceita em10 de julho de 2004 